\title{
Human Suicide Study, is there an Association between Suicide and Mental Illness?
}

\author{
Da-Yong Lu ${ }^{1 *}$, Peng-Peng Zhu ${ }^{2}$, Hong-Ying Wu ${ }^{1}$, Nagendra Sastry Yarla ${ }^{3}$, Hong Zhu ${ }^{4}$ and Jin-Yu Che ${ }^{1}$ \\ ${ }^{1}$ Shanghai University, Shanghai 200444, PR China \\ ${ }^{2}$ Cellular Neurology Unit, NINDS, National Institute of Health, Maryland, USA \\ ${ }^{3}$ GITAM University, Viskhapatnam, Andhra Pradesh, India \\ ${ }^{4}$ Zhejiang University, Zhejiang, PR China
}

\begin{abstract}
Since suicide is a causality of a lot of human mortalities worldwide, its therapeutic study is of great medical significance. Yet human suicide predictions and preventions are still difficult until now. As a result, it needs to find out new ways of solving this dilemma. As human suicide etiological/pathologic undertaking is quite necessary, human suicide treatments can be better transformed from clinical symptom observations into new generations of therapeutics-mental illness-related diagnostics and therapeutics. In future, better clinical suicide predictions, preventions and therapeutic managements can be established via pathways of human mental illness studies.
\end{abstract}

Keywords: Psychiatric disorders; Human genome; Neural pathogenesis; Environmental factors; Bioinformatics; Medicinal chemistry; Human suicide

\section{Introduction}

Suicide is a major causality of human mortality across the world. Yet human suicide predictions and preventions are difficult to obtain. As a result, in order to find out new ways of solving this situation, human suicide etiological/pathologic study is quite necessary. Previously, human suicide was commonly regarded as a clinical symptom rather than an aspect of human mental illness-related disease that can be traceable from biological or genetic tangible existence discoveries. In order to clarify this matter of etiological/pathologic enigma, we document some events of historic literatures, medical ways of suicide probing and different types of counteractive measure promotions. After all, genetic/molecular clues available for suicidal linkage between pathogenesis and therapeutics will be established. From these avenues, better clinical suicide predictive systems and therapeutic managements would be invented in future.

\section{Suicide Causalities}

\section{Mental disorder arguments}

As suicide is not the name of disease category, the possible origin will be traced to several causalities. Human mental health problems are the most important one. From Table 1, we can see a close association between suicide and mental disorders (Table 1). Therefore, mental disorder diagnostics for suicide patients and therapeutics are exemplified.

Currently, estimated $10-20 \%$ of general human population is suffered from mental health problem and disorders. 1/4 of human beings seeking primary medical care are caused by mental illnesses, especially mood disorders. Despite high incidence, common therapeutic outcomes are generally unsatisfactory [1,2]. Mental health problems are often life-long (chronic disorder). Unfortunately, human depression (majority of human mental health problem, brain disorder) epidemics have been steadily growing in the past decades [3-6]. Varying suicide risks and rates among different types of mental diseases, such as mood depression, bipolar or dysthymia make disease interventions more complicated [7]. As a result, the costs for antidepressant therapies are rising because large proportion of human beings suffers depression in high competitively modern society that has negative feedbacks by social isolations [8].

\section{Other causalities}

A range of social/environmental factors can decide human suicide rates and mortalities. Unveiling the interplay between insider (human genetics and chemical structures of drugs) and outsider (multifactorial economic, social, past bad habits or trauma) is the top priority [9]. However, small-range positive data from relevant medical managements have been repeated, let alone breakthroughs on this medical field. Generally, reducing from social/environmental pressure seems more beneficial than chemical drug-based therapies because so many factors affect efficacy or outcomes of drug therapeutics nowadays; outlines this matter (Table 2) [10-13].

Suicide/mental illness diagnostics generally depends on analysis of patient's mood symptom degree-depression and mania.

\section{Suicide/Mental Illness Diagnostics}

From the disease diagnosis, the symptoms of human suicide risks (hopeless feeling, self-deny and so on) are very similar with symptoms of mental illnesses (hopeless and helpless), especially mood disorder (Table 2). The outsider insults of environmental factors for suicide are also very similar with outsider insults for mental illnesses-including marriage problems or lost of jobs and so on. Since no conclusive outcomes from past suicide pathogenesis molecular/pathways have been understood and generally agreed, we hypothesized that mental illnesses may have some associations with suicide risks, events or mortalities. By human mental illness diagnostic or therapeutic studies, we may enhance out abilities for suicide predictions and preventions.

*Corresponding author: Lu DY, Shanghai University, Shanghai 200444, PR China, Tel: 18262587428; E-mail: ludayong@shu.edu.cn

Received September 07, 2016; Accepted September 16, 2016; Published September 19, 2016

Citation: Lu DY, Zhu PP, Wu HY, Yarla NS, Zhu H, et al. (2016) Human Suicide Study, is there an Association between Suicide and Mental Illness? Metabolomics (Los Angel) 6: 186. doi: 10.4172/2153-0769.1000186

Copyright: (c) 2016 Lu DY, et al. This is an open-access article distributed under the terms of the Creative Commons Attribution License, which permits unrestricted use, distribution, and reproduction in any medium, provided the original author and source are credited. 


\begin{tabular}{|c|c|c|c|}
\hline \multicolumn{2}{|c|}{ Worldwide; totally 15,629 cases } & \multicolumn{2}{|c|}{ UK; totally 4,859 cases } \\
\hline $\begin{array}{c}\text { Mood disorders } \\
\text { Substance disorders } \\
\text { Personality disorders } \\
\text { Schizophrenia } \\
\text { Anxiety disorders }\end{array}$ & $\begin{array}{l}35 \% \\
22 \% \\
12 \% \\
11 \% \\
6 \%\end{array}$ & $\begin{array}{l}\text { Mood disorders } \\
\text { Schizophrenia } \\
\text { Personality disorders } \\
\text { Alcohol dependent } \\
\text { Drug dependent } \\
\text { Anxiety disorders }\end{array}$ & $\begin{array}{l}42 \% \\
20 \% \\
11 \% \\
9 \% \\
4 \% \\
3 \%\end{array}$ \\
\hline Other disorders & $14 \%$ & Other disorders & $11 \%$ \\
\hline
\end{tabular}

Table 1: The linkage between suicide and other diseases [1]

\begin{tabular}{|c|c|c|c|}
\hline Contents & \multicolumn{3}{|c|}{ Different categories of diagnosis and therapeutics } \\
\hline Nominations & Unipolar & Bipolar I & Bipolar II \\
\hline Symptoms & Depression & Mania & $\begin{array}{c}\text { Depression + } \\
\text { Mania }\end{array}$ \\
\hline Current diagnosis & Symptom-based diagnostics (Score index and so on) \\
\hline $\begin{array}{c}\text { Under } \\
\text { investigations }\end{array}$ & \multicolumn{3}{|c|}{ Genetics-, molecular- or visual-based diagnostics } \\
\hline Future diagnostics & \multicolumn{3}{|c|}{ Diagnosis from multi-disciplinary } \\
\hline Therapeutics & $\begin{array}{c}\text { Antidepressants? } \\
\text { Such as (SSRIs) }\end{array}$ & $\begin{array}{c}\text { Mood stabilizers } \\
\text { Anti-Psychotics }\end{array}$ & $\begin{array}{c}\text { Antidepressants + } \\
\text { Mood stabilizers }\end{array}$ \\
\hline Drawbacks & Controversy & $\begin{array}{c}\text { Side-effects for } \\
\text { long-term } \\
\text { Utilities }\end{array}$ & $\begin{array}{c}\text { Lack of } \\
\text { systematical } \\
\text { Clinical } \\
\text { assessments }\end{array}$ \\
\hline
\end{tabular}

Table 2: General procedures for mood disorder diagnostics and therapeutics.

\section{Symptom checklist for diagnosis of depressive episode}

- Persistent low $\operatorname{mood}^{1}$

- Loss of interest or pleasure ${ }^{1}$

- Fatigue or low energy ${ }^{1}$

- Disturbed sleep

- Poor concentration or indecisiveness

- Poor or increased appetite

- Suicidal thought or act

- Agitation or slowing of movement

- Guilt or self-blame

- Low self-confidence

\section{Major checklist for diagnosis of mania symptoms}

- Flight of ideas

- Distractibility

- Risky decision-making

Following scenarios are general data of possible suicide/mood problems from diagnostics into therapeutics. Detail diagnostic information can be found in Diagnostic and Statistical Manual of Mental Disorder-from DSM-I to DSM-V of mood problems and Hamilton Depression Rating Scale (HAM-D) of suicide risks.

The major pathways of disease therapeutics

(i) Increase the support and backup of patients. Thus patients may go through outside stressors;

(ii) Cognitive-behavior therapy;

(iii)Chemotherapeutic agents or drugs;

${ }^{1}$ Represents the especial importance. (iv) Cut off access to suicide tools from patients at high suicide risks.

The cognitive-behavior is the widely utilized therapy in mental illness treatments, which is largely based on psychiatrists-patients conversations.

For targeted chemotherapy applications, etiologic or pathogenesis mechanisms and molecular processes must be fully understood [1213]. To attain this goal, etiological/pathologic/phenotypic quests for diagnostic updating are the first step. Following scientific pathways are noteworthy. In most serious patients, chemical drug therapy is needed.

\section{Suicide Origins and Pathologic Linkages}

Overall, diagnostic or therapeutic model updating must be useful from environmental/pathological information-seeking medications from multi-disciplinary [14]. To attain this goal, genetic-/molecular/ visual-based diagnostics by clinical teamwork is the key.

Currently, some effective clinical suicide/mental health problem interventions come from environmental condition benefiting rather than long-term drug utilities. At this stage, widely used drugs have some toxicity by long-term utilities. Equally, antidepressants or others are sensitive to some parts of patients and it even induces suicide events in other population [15-21]. This is an important discovery. We previously explained as a matter of human genetic predisposition variations [20-23]. To completely solve this dilemma, etiological/ pathological tangible causalities must be found out. Although its medical significance is big, the genetic/molecular/morphologic-based pathogenesis information needs to be greatly updated. Quick diagnosis of suicide/mental illness is no easy a task owing to symptom similarity (depression or mania) between normal humans and mental health problem patients. Let alone capture the disease stages and types. Yet modern biological techniques and systems (genomic/omics) are advantage at these items of pathogenesis diagnosis [24-27].

Suicide/mental illness may undergo long-terms latency and evolution. Once a patient seeks medical advises, the disease may have been initiated for several years. The earliest medical interventions may be paradigms for symptom controls and/or better disease managements if possible. Diagnostics of diseases by modern techniques may be a shortcut for achieving this goal in early literatures. At least $90 \%$ of suicide subjects suffer from mental illnesses. $15 \%$ of depressed subjects have attempted suicide at least once life-long. 20-50\% schizophrenia patients have at least one suicide episode in whole life-time [28]. Understanding the relationship between suicide and mental illnesses is a future trend for suicidal event predictions and preventions.

\section{Etiological/Pathologic Knowledge and Modern Drug Development Establishment}

Bioinformatics studies consist of a number of different categories of biological information, such as transcriptomics, proteomics, and metabolomics and so on. Although bioinformatics in suicide risk predictions has been initially studied, no marked breakthrough has been achieved until now [24]. Along with other technologies, various chemical drugs supported by modern techniques, such as SSRIs-kind of targeted antidepressants are going smoothly nowadays.

\section{Methodologies in advance}

The best candidate genetic or molecular information for suicide/mental illness therapy predictions are unclear now. Genetic associations between drug-active and drug-toxic genes (molecules) 
might be optimized by in-depth scientific investigations towards the core of patient's suicides and self-injuries. Adapting new techniques into the clinical suicidal studies is indispensable and noteworthy. Other current achievements relating chemical drug developments and clinical applications are partly offered in followings (Table 3). Some of these new techniques have already been widely utilized in mental disorder drug studies and licensing.

\section{Technical Supportive Systems}

Generally speaking, a proper treatment of the central nervous system diseases is not a easy task. In many suicide cases, mental disorder diagnostics is complex in pathological patterns, long-term suffering and a wide variety of therapeutic options. Once a person has been diagnosed with moderate-to-severe mental disorder, he/or she will usually have to take drug medication lifelong because this is a chronic disease now. Thus, relationships between pathogenesis and therapeutics in modern ways must be established. Theoretically, this recent model of therapeutics is possible, yet long way to go [28]. In our opinion, Personalized Medicine (PD) of suicide/mental disorders by Pharmacogenetics (PG) data is still immature now. It is rarely seen a high quality of genome/bioinformatics/visual diagnostic system in general hospitals. But new techniques and statistical analytical systems are gradually coming into the reality now.

\section{Diagnostic/therapeutic relationship buildup}

Currently, the drug selections for mental health problems are still decided by symptom-index systems rather than many objective data (genomic/bioinformatics/visual), let alone social/economic/habit factors or conditions. Since symptom-indexed systems are subjective rather than objective, integrating disease progression status by modern techniques (genetics/bioinformatics/visual) is important. In order to achieve such a goal, great deal of foundation studies of both neuralpsychiatry profiling and target therapeutics must be undertaken first.

The polymorphisms of drug targets or toxicity genes in patients' genomes must be identified and verified for PG utilities. Similarity and diversity relationship among suicide risk, mental disorder severity, chemical drug metabolism and target drug (signal-, receptors and

\begin{tabular}{|c|c|}
\hline Research fields & Major technologies \\
\hline Biological & $\begin{array}{c}\text { Gene knockout } \\
\text { Optogenetics } \\
\text { Genomic editing } \\
\text { Brain volume and image study }\end{array}$ \\
\hline Pathogenesis & $\begin{array}{c}\text { Disease classifications } \\
\text { Genetic-visual relations } \\
\text { Gene knockout } \\
\text { Gene-environment interactions }\end{array}$ \\
\hline Experimental models & GEM \\
\hline Genomic & $\begin{array}{c}\text { SNP (Microarray) } \\
\text { PCR-based diagnostics } \\
\text { Genome wide association studies }\end{array}$ \\
\hline Bioinformatics & $\begin{array}{c}\text { Transcriptomics } \\
\text { Proteomics } \\
\text { Metabolomics } \\
\text { Computational network }\end{array}$ \\
\hline Drug developments & $\begin{array}{c}\text { Medicinal chemistry } \\
\text { Analytical chemistry } \\
\text { Pharmacology } \\
\text { Statistics }\end{array}$ \\
\hline Clinical therapeutics & $\begin{array}{c}\text { Cerebral image } \\
\text { Personalized medicines } \\
\text { Computational network }\end{array}$ \\
\hline
\end{tabular}

Table 3: Methodology applications and under investigations for suicide diagnosis and therapy [23]. so on) must be understood. Useful patents or licensed drugs can be promoted into clinical utilities.

A great number of patient's genomic predisposition has been accumulated after the advent of Next-Generation-Sequencing (NGS) technologies. Accumulating and comparisons between inheritable disease-cases and normal human population by GWAS (Genome Wide Association Study) data is general pathway for neural/mental illness therapeutics and toxicity/risk predictions [29-33]. GWAS of chemical or biotherapy might have profound impacts on science and technology developments. By taking GWAS, larger than ten genetic allele variations between normal humans and mental disordered patients has been found ( $>500$ patient genomic samples). GWAS is a basic pathway for translating novel therapeutics from bench to the bedside. To make greater leaps, GWAS of chemical drug therapy must be studied as early as possible. The statistical analysis of genomic data and therapeutics relates with sample size. To our understanding, biomedical students are not adept with these processes. Many post-genome analysis needs to be explained by a few world-leading institutes, universities or biological companies [34-35]. Our humble imagination suggests that genome sequencing working and research forces might be gradually changed from biomedical major students into mathematic or physics major students or scholars [36-37]. The contributions by mathematics and physics students or scholars for genomic sequencing may be more significant than biomedical majored students because of larger genomic data manipulations or analysis demanding in GWAS [38-39].

\section{Brain structural and neural-imaging studies}

Since human suicide/mental illness are probably brain diseases, it is believed and partly discovered that brain image changes of both volumetric and cerebral regional compartments (prefrontal or cingulated cortex and so on) can be generally observed by brain imaging scanning by techniques of Position Emission Tomography (PET), Single-Photon Emission Computed Tomography (SPECT) or functional Magnetic Resonance Imaging (fMRI) [5]. The changes in cortical and sub-cortical areas have been discovered. As a result, divergent techniques of neural imaging studies of both experimental and clinical are taken together to identify these cerebrally morphological changes and guide further therapeutic targets [6]. More recently, 70\% false-positive data has been found in brain scan study [38]. It can be a technical drawback, software imperfection or en no mistake at all. As a result, whether effective drug can act on brain area changes are still an open question waiting to be answered.

\section{Gene-environment interaction studies}

Previously, we commonly believe that patient's genetic predisposition is independent of environmental conditions. Yet, it has been found since 2003 that environment impacts, such as bad past experience and trauma in early stage can modulate gene expression, especially epigenetic context in humans [28]. Many genes, molecules, receptors linking with serotonergic systems or others can be changed by different kinds of environmental insults and impacts. In early reports, epigenetic entities can be dramatically changed in mentalillness patients or sufferers after a big trauma.

\section{Modern pharmacological studies}

A number of chemical drugs (mood stabilizers, anti-psychosis, antidepressants and so on) are clinical utilized [12-13]. Two major drawbacks are present-low specificity against disease progresses and moderate-to-severity toxicities for long-term utilities. As a result, they are often utilized at the stage of patient's hospitalizations. In order to change this situation, novel animal models, state-of-the-art 
Citation: Lu DY, Zhu PP, Wu HY, Yarla NS, Zhu H, et al. (2016) Human Suicide Study, is there an Association between Suicide and Mental Illness? Metabolomics (Los Angel) 6: 186. doi: 10.4172/2153-0769.1000186

lab instruments and equipments must be utilized. Certainly, these scientific researches need larger patient's genetic pools and GWAS between normal and mental health problem peoples.

\section{Neuroscientists, neurosurgeons and pathologists in mental health diagnostic and treatment studies}

Since suicide/mental health problem is probably a brain disease, neuroscientists, neurosurgeons or pathologists who are trained to tackle brain morphological change analysis may be the major forces to remedy neural dysfunctions [3-6,39]. Their importance is beyond doubts (Figures 1 and 2).

\section{Conclusion}

Growing attentions should be paid on different possibilities of diagnostic and therapeutic updating. The relationships between chemical, genetic, molecular, morphologic, neurologic, environmental, social and cultural factors for pharmacological and therapeutic improvements should be considered and investigated both individually and as a whole. It can be through genetics to molecular to visual or via visual to molecular to genetics. To attain this achievement, technical updating is noteworthy. Facing this challenge, searching for suiciderelated biologically tangible molecules/entities is the key.

\section{New compound development pipelines}

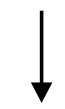

\section{Structural or configuration studies}

(Spectra and microscopy)

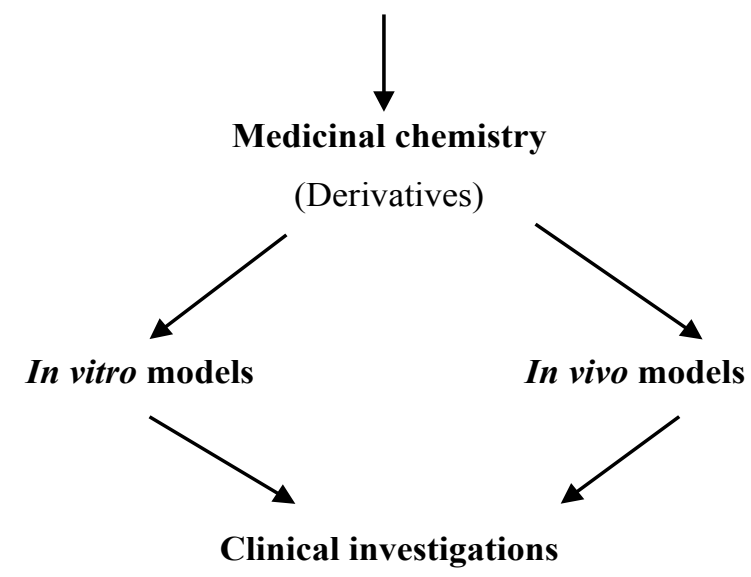

(Genetic-, molecular-, brain volume/image and so on)

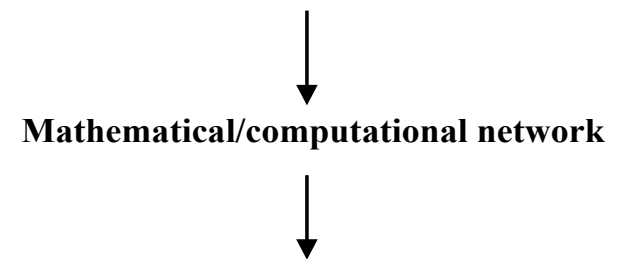

\section{Cost-effective considerations}

Figure 1: Schematic pathways for response and toxicology of chemical drug developments and treatment studies.
Literature and book surveys

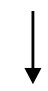

Establishments of useful experimental models

(From rodents into primates)

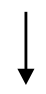

Comparisons of mechanisms of action between early and new drugs

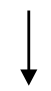

Updating diagnostic manual

(Multi-disciplinary)

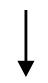

Therapeutic combination study

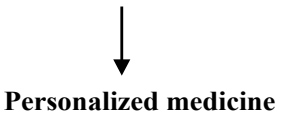

Figure 2: A diagram of future suicide study and treatment paradigm originations.

\section{Acknowledgements}

This work was funded by Shanghai Science and Technology Foundation of High Educations 97A49

\section{Conflict of Interests}

Authors declare there is no conflict of interests with other institutes and academies.

\section{References}

1. Kapur N, Gask L (2009) Introduction to suicide and self-harm. Psychiatry 8: 233-236.

2. Haddad M, Walters $P$, Tylee A (2009) Mood disorders in primary care. Psychiatry 8: 71-75.

3. Frangou S (2009) Brain structural changes in mood disorders. Psychiatry 8 105-106.

4. Roiser JP, Rubinsztein JS, Sahakian BJ (2009) Neuropsychology of affective disorders. Psychiatry 8: 91-96.

5. Frangou $S$ (2008) Functional neuroimaging in mood disorder. Psychiatry 6 : 102-104.

6. Desmyter S, Bijttebier S, Heeringen KV (2013) The role of neuroimaging in our understanding of the suicidal brain. CCNS Neurol Disord Drug Targets 12 : 921-929.

7. Kendell R (2006) Diagnosis and classification of mood disorders. Psychiatry 5: 112-114.

8. Patel A (2009) The cost of mood disorders. Psychiatry 8: 76-80.

9. Lu DY, Lu TR, Zhu PP, Che JY (2016) The efficacies and toxicities of antidepressant drugs in clinics, building the relationship between Chemo-Genetics and SocioEnvironments. Cent Nerv Syst Agents Med Chem 16: 12-18.

10. Morriss R (2009) Psychological models of mood disorders. Psychiatry 8: 82-86

11. Sueki $H$ (2015) Suicide prevention using the Internet; mini-review and case study in online gate-keeping activity. Suicidal Ideation: Predictors, Prevalence and Prevention. Ed. Bradley Weaver. Nova Science Publishing. US, Chapter 5, pp 85-100.

12. McAllister-Williams R, Ferrier IN (2009) Pharmacological management of unipolar affective disorder. Psychiatry 8: 113-119. 
Citation: Lu DY, Zhu PP, Wu HY, Yarla NS, Zhu H, et al. (2016) Human Suicide Study, is there an Association between Suicide and Mental Illness? Metabolomics (Los Angel) 6: 186. doi: 10.4172/2153-0769.1000186

Page 5 of 5

13. McAllister-Williams RH, Ferrier IN (2009) Pharmacological management of bipolar affective disorder. Psychiatry 8: 120-124.

14. Lu DY, Zhu PP, Lu TR, Che JY (2016) The suicidal risks and treatments, seek medications from multi-disciplinary. Cent Nerv Syst Agents Med Chem.

15. Rubino A, Roskell N, Tennis P, Mines D, Weich S, et al. (2007) Risk of suicide during treatment with venlafaxine, citalopram, fluoxetine, and dothiepin: retrospective cohort study. BMJ 334: 242-247.

16. Kovacs D, Gonda X, Petschner P, Edes A, Eszlari N, et al. (2014) Antidepressant treatment response is modulated by genetic and environmental factors and their interactions. Ann Gen Psychiatry 13: 17.

17. Teicher MH, Glod C, Cole JO (1990) Emergence of intense suicidal preoccupation during fluoxetine treatment. Am J Psychiatry 147: 207-210.

18. Tsai SJ (2005) Possible involvement of the BDNF-dependent pathway in the treatment-emergent suicidality or decreased response to antidepressants. Med Hypotheses 65: 942-946.

19. Lu DY, Lu TR, Ding J (2007) May genetic factors play a role in the risk of antidepressant-induced suicide. Med Hypotheses 69 1380-1381.

20. Lu DY, Lu TR, Zhu PP (2010) Undesired neural side-effects of a drug, a chemical and genetic interrelated problem. Cent Nerv System Agent Med Chem 10: 108-112.

21. Lu DY, Lu TR (2011) Importance of genomic studies for drug withdrawal with mental illness. Drug Therapy Studies 1: e11.

22. Lu DY, Lu TR, Che JY, Zhu PP (2014) Genetics and bioinformatics studies of antidepressant drug therapeutic efficacies and toxicities, a current overview. Recent Pat. CNS Drug Discov 9: 193-199.

23. Lu DY, Lu TR, Zhu PP, Che JY (2015) Genetics and bioinformatics study of antidepressant drugs, recent advancements and future trends. Suicidal Ideation: Predictors, Prevalence and Prevention. Ed. Bradley Weaver. Nova Science Publishing. US, Chapter 3, pp: 57-71.

24. Brent D, Melhem N, Turecki G (2010) Pharmacogenomics of suicidal events Pharmacogenomics 11: 793-807.

25. Lu DY, Lu TR, Zhu PP (2012) How can we pinpoint genetic involvement in antidepressant-induced suicide? Adv Pharmacoepidemiol Drug Safety 1: e101.
26. Lu DY, Lu TR, Zhu PP (2012) Genetics in neural toxicities of drugs. Cent Nerv Syst Agents Med Chem 12: 250-253.

27. Lu DY, Lu TR, Zhu PP (2013) Pharmacogenetics in neural toxicities of drugs Pharmacogenomics 14: 1129-1131.

28. Serafini G, Salano P, Amore M (2015) Suicidal ideation: a comprehensive overview. Suicidal Ideation: Predictors, Prevalence and Prevention. Ed. Bradley Weaver. Nova Science Publishing. US, Chapter 1, pp: 1-42.

29. Menke A, Samann P, Kloiber S, Czamara D, Lucae S, et al. (2012) Polymorphisms within the metabotropic glutamate receptor 1 gene are associated with depression phenotypes. Psychneuroendocrinology 37: 565-575.

30. Laje G, Allen AS, Akula N, Manji H, Rush AJ, et al. (2009) Genome-wide association study of suicidal ideation emerging during citalopram treatment of depressed outpatients. Pharmacogenet Genomics 19: 666-674.

31. Garriock HA, Kraft JB, Shyn SI, Peters EJ, Yokoyama JS, et al. (2010) A genome wide association study of citalopram response in major depressive disorder. Biol Psychiatry 67: 133-138.

32. Uher R, Perroud N, Ng MY, Hauser J, Henigsberg N, et al. (2010) Genomewide pharmacogenetics of antidepressant response in the GENDEP project. Am J Psychiatry 167: 555-564.

33. Menke A, Domschke K, Czamara D, Klengel T, Hennings J, et al. (2012) Genome-wide association study of antidepressant treatment-emergent suicidal ideation. Neuropsychopharmacology 37: 797-807.

34. Lander ES (2011) Initial impact of the sequencing of the human genome Nature 470: 187-197.

35. Maher B (2011) Genomes on prescriptions. Nature 478: 22-24.

36. Lu DY, Lu TR (2015) Mathematics or physics-majored students on the biomedical fields, insiders or outsiders? Metabolomics 6:1.

37. Lu DY, Wu HY, Lu TR, Che JY, Lu Y (2016) Updating biomedical studies by recruiting more mathematics or physics-majored talents. Metabolomics 6: e148.

38. Miller G (2016) Brain scans, a prone to false positive study says. Science 353: 209

39. Read J, Runciman O, Dillon J (2016) In search of an evidence-based role for psychiatry. FSOA 2: 2015-0011. 